\title{
Modelling the transmission dynamics of severe fever with thrombocytopenia syndrome in Jiangsu Province, China
}

Nan Zhang ${ }^{1+}$, Xiao-Qing Cheng ${ }^{1 \dagger}$, Bin Deng ${ }^{2 \dagger}$, Jia Rui ${ }^{2 \dagger}$, Luxia Qiu², Zeyu Zhao ${ }^{2}$, Shengnan Lin², Xingchun Liu², Jingwen $\mathrm{Xu}^{2}$, Yao Wang ${ }^{2}$, Meng Yang ${ }^{2}$, Yuanzhao Zhu'², Jiefeng Huang ${ }^{2}$, Chan Liư ${ }^{2}$, Weikang Liu² Li Luo², Zhuoyang $\mathrm{Li}^{2}$, Peihua $\mathrm{Li}^{2}$, Tianlong Yang ${ }^{2}$, Zhi-Feng Li', Shu-Yi Liang ${ }^{1}$, Xiao-Chen Wang ${ }^{1}$, Jian-Li Hu ${ }^{1 *}$ and Tianmu Chen ${ }^{2^{*}}$ (D)

\begin{abstract}
Background: Severe fever with thrombocytopenia syndrome (SFTS) is an emerging infectious disease that is regionally distributed in Asia, with high fatality. Constructing the transmission model of SFTS could help provide clues for disease control and fill the gap in research on SFTS models.

Methods: We built an SFTS transmission dynamics model based on the susceptible-exposed-infectious-asymptomatic-recovered (SEIAR) model and the epidemiological characteristics of SFTS in Jiangsu Province. This model was used to evaluate the effect by cutting off different transmission routes and taking different interventions into account, to offer clues for disease prevention and control.
\end{abstract}

Results: The transmission model fits the reported data well with a minimum $R^{2}$ value of 0.29 and a maximum value of $0.80, P<0.05$. Meanwhile, cutting off the environmental transmission route had the greatest effect on the prevention and control of SFTS, while isolation and shortening the course of the disease did not have much effect.

Conclusions: The model we have built can be used to simulate the transmission of SFTS to help inform disease control. It is noteworthy that cutting off the environment-to-humans transmission route in the model had the greatest effect on SFTS prevention and control.

Keywords: Severe fever with thrombocytopenia syndrome, Bunyavirus, Mathematical model, Environment, Ticks, Transmission, Dynamic

*Correspondence: jshjl@jscdc.cn; 13698665@qq.com

${ }^{\dagger}$ Nan Zhang, Xiao-Qing Cheng, Bin Deng and Jia Rui contributed equally to this work

1 Department of Acute Infectious Diseases Control and Prevention, Jiangsu Provincial Centre for Disease Control and Prevention, 172, Jiangsu Rd, Nanjing 210009, China

${ }^{2}$ State Key Laboratory of Molecular Vaccinology and Molecular Diagnostics, School of Public Health, Xiamen University, Xiamen 361102,

Fujian, People's Republic of China

\section{Background}

Severe fever with thrombocytopenia syndrome (SFTS) is an emerging infectious disease caused by a novel bunya virus called severe fever with thrombocytopenia syndrome virus (SFTSV) [1]. The clinical manifestations of infection in human are characterized by high fever, a drastic reduction of platelets and leukocytes and hemorrhage [2-5]. The clinical course is mainly divided into three stages: fever, multiple nerve dysfunction and recovery $[1,3,4,3,7]$.

c) The Author(s) 2021. This article is licensed under a Creative Commons Attribution 4.0 International License, which permits use, sharing, adaptation, distribution and reproduction in any medium or format, as long as you give appropriate credit to the original author(s) and the source, provide a link to the Creative Commons licence, and indicate if changes were made. The images or other third party material in this article are included in the article's Creative Commons licence, unless indicated otherwise in a credit line to the material. If material is not included in the article's Creative Commons licence and your intended use is not permitted by statutory regulation or exceeds the permitted use, you will need to obtain permission directly from the copyright holder. To view a copy of this licence, visit http://creativeco mmons.org/licenses/by/4.0/. The Creative Commons Public Domain Dedication waiver (http://creativecommons.org/publicdomain/ zero/1.0/) applies to the data made available in this article, unless otherwise stated in a credit line to the data. 
In previous years, SFTS occurred mainly in the rural areas of central and northeast China, with an estimated 500-1500 cases recorded in 2011-2012. Over time, SFTS has spread to South Korea and Japan, although the related fatality rate of nearly $30 \%$ has dropped to $10-12 \%$ in recent years [8]. In South Korea, the fatality rate was above 35\% among infected patients in 2012-2013, but the incidence rate dropped to $11.52 \%$ in 2016 [9]. In Japan, however, the fatality rate is slightly higher than that observed in China (23\%), and cases have mainly occurred in the western regions [10]. Currently, the SFTS fatality rate in Asia seems to be decreasing, while the incidence rate is increasing regionally, especially in China. According to the monitoring data from the China Information Network System of Disease Prevention and Control, SFTS incidence and prevalence rates have increased each year from 2010 to 2016, with cases found in 23 provinces [11]. Analyzing the epidemiological characteristics of SFTS, one published study found Henan Province, Hubei Province and Anhui Province to be the main provinces with the largest numbers of cases before 2011 [12]. Including five other provinces, SFTS cases were detected in Jiangsu Province as far back as 2011 [13]. Since then, the number of SFTS cases reported in Jiangsu Province has increased annually, with more than 140 confirmed cases in over 60 locations within the province by 2016 [14].

To fight against this emerging infectious disease, findings from both domestic and foreign research on the etiology and risk factors of the disease are of great importance. As shown by these study findings, SFTS mainly occurred in tick-active months from May to September, and reports of new infections continued until November. The main population affected by SFTS is farmers aged 50 years old and above who live in forested or hilly areas [15-18]. Recent researches suggested that ticks are the main host of SFTS and play a key role in its transmission. Haemaphysalis longicornis, Ixodes nipponensis, Rhipicephalus microplus and Dermacentor sinicus, amongst others, are the susceptible ticks identified, but Haemaphysalis longicornis is the dominant species [1, 19-22]. While SFTS cases occurred from March to November, the disease period peaked in August and September. The seasonal distribution of SFTS cases was also found to be closely related to the seasonal trend of tick density [23, 24]. Some preliminary researches exist to show the process of host animal-tick-human natural transmission routes of SFTS [25]. However, there are very few systematic and definite researches on transmission routes among vector, host and SFTSV-affected populations. Meanwhile, various problems exist in the treatment of SFTS such as unclear pathogenesis, absence of vaccine for prevention and lack of a specific SFTS antiviral therapy. As a result, a low fatality rate cannot be maintained.

SFTS infection also induces a certain amount of economic pressure on affected populations, as a study has shown that patients and their families pay nearly $\$ 3158.4$ for treatment [2]. This makes SFTS a significant threat to public health, as the treatment amount is almost equal to the disposable income of rural residents in Anhui Province as of 2017 [2]. To date, no research exists on a transmission dynamics model of SFTS, and there is no clear evidence on preventive methods that could help achieve optimal intervention effects.

This study aimed to construct a multi-population and multi-route dynamic model (MMDM) based on the susceptible-exposed-infectious-asymptomatic-recovered (SEIAR) model, the epidemiological characteristics and the transmission features of SFTS in Jiangsu Province.

\section{Methods}

Study area

Jiangsu Province is located between $30^{\circ} 45^{\prime}$ and $35^{\circ} 20^{\prime}$ north latitude and $116^{\circ} 18^{\prime}$ to $121^{\circ} 57^{\prime}$ east longitude (Additional file 1: Figure S1). Jiangsu Province is located in the East Asian monsoon climate zone, in the transitional zone between subtropical and warm temperate climate. The total area of Jiangsu Province is 107,200 square kilometers, with an estimated permanent population of 80.7 million as of the end of 2019 .

\section{Study design}

This study was designed by three steps. First step, the MMDM model of SFTS was established by searching scientific literature and analyzing reported data. Second step, the reported data of SFTS in Jiangsu Province from January 2001 to December 2019 was used to fit the developed model. Third step, the MMDM model was used to simulate the intervention effect of eliminating different routes of transmission. This was achieved by setting the parameters of the model to obtain the best intervention plan, thus providing clues to effective disease control interventions and filling the gap in the research on SFTS models (Fig. 1).

\section{Establishment of transmission dynamics model}

Based on the characteristics of epidemic and the routes of transmission of SFTS in Jiangsu Province and the SEIAR model [14, 26-28], this study established the MMDM to simulate SFTS transmission. This model included four parts, namely human, ticks, host animals and environment, which are represented by subscript 1, 2, 3 and $w$, respectively (Fig. 2). 


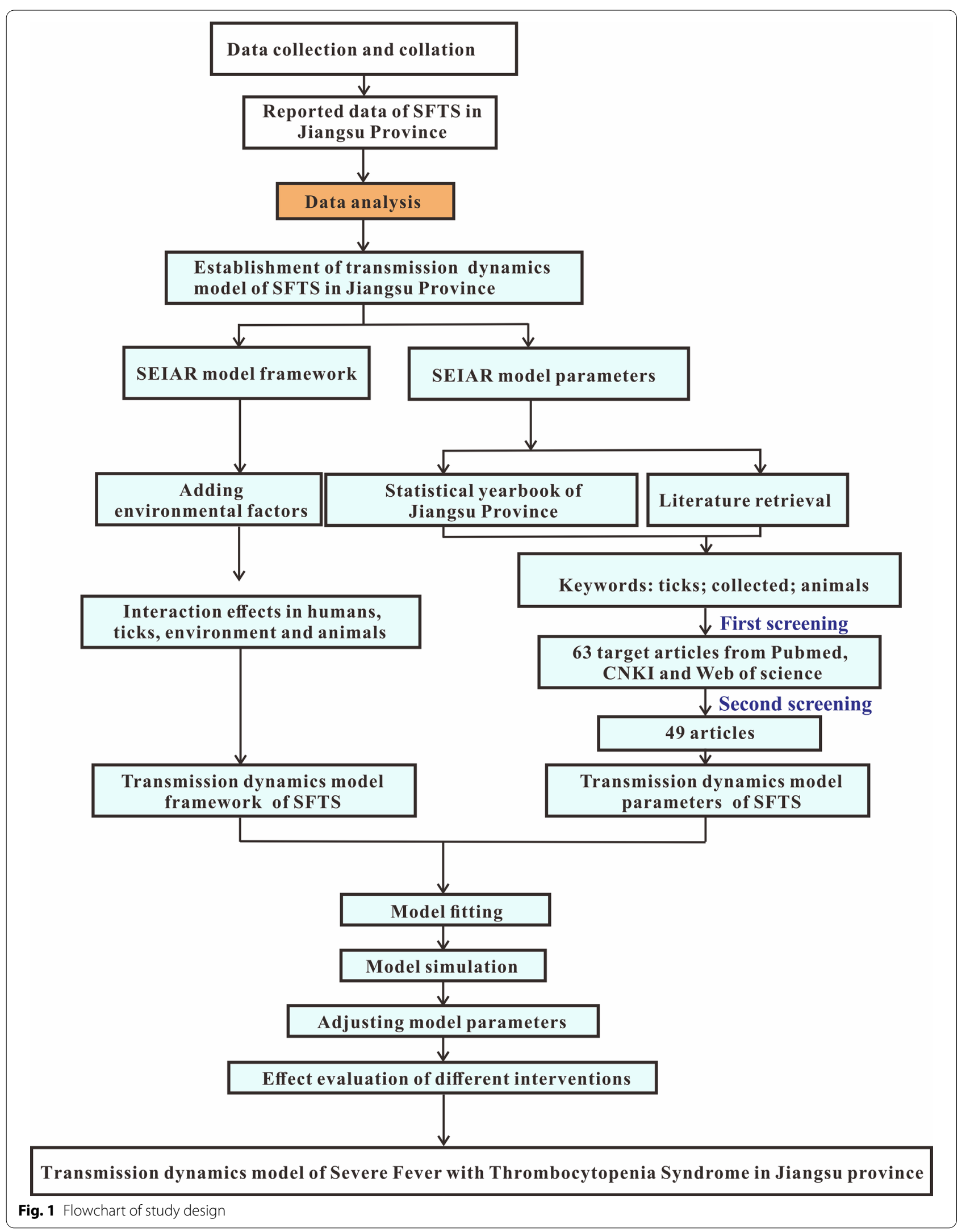




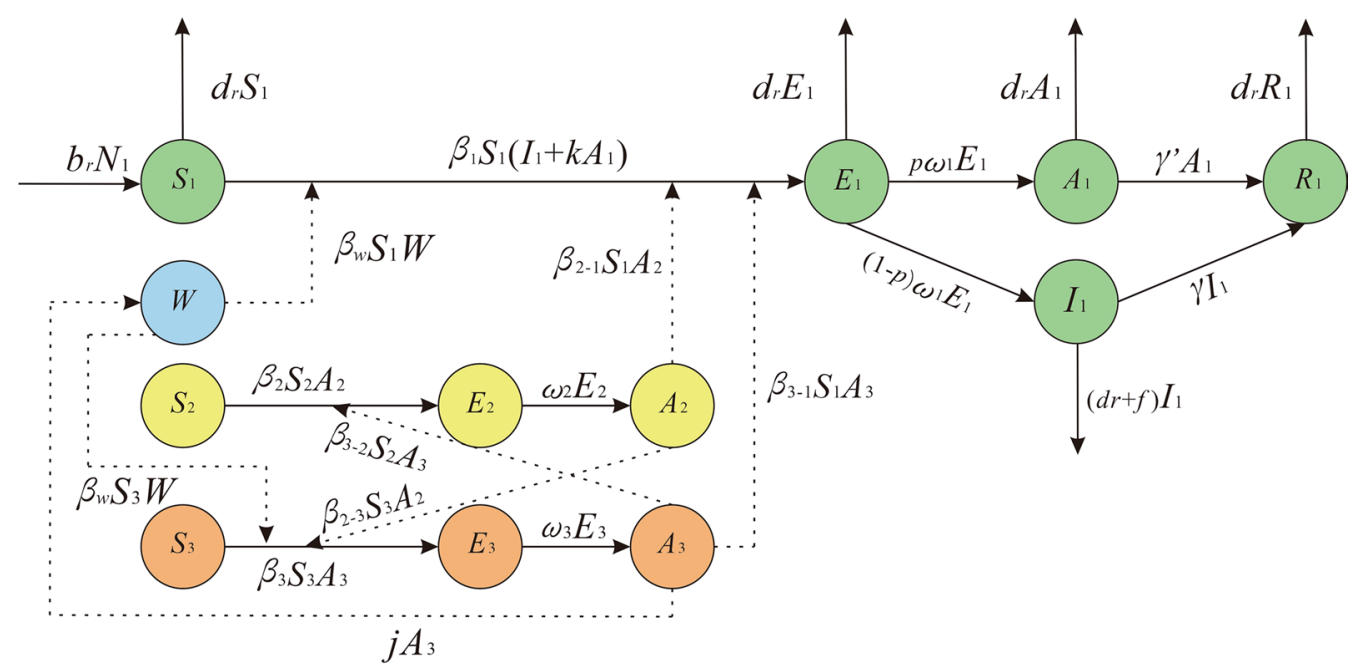

Fig. 2 Flowchart of the MMDM without intervention

\section{Human part of the MMDM}

In this part, humans were categorized as: susceptible $\left(S_{1}\right)$, exposed $\left(E_{1}\right)$, asymptomatic $\left(A_{1}\right)$, infectious $\left(I_{1}\right)$ or recovered/remover $\left(R_{1}\right)$. The structure of the MMDM is shown in Fig. 2, and this part of the MMDM was based on the following assumptions:

1. This model supposed that all human newborns are susceptible to the disease. Under this assumption, the total population is denoted by $N$, the birth rate is $b r$ and the natural mortality rate is $d r$. According to the literature, the fatality rate of overt infections, $f$, is $16.1 \%$ [5]. Meanwhile, this model took the population-wide mortality rate to approximately replace the mortality rate of the excluded overt infections.

2. According to the literature, people can be infected with SFTS by coming in contact with the blood of an infected patient [29]. At the same time, the transmissibility of $I_{1}$ and $A_{1}$ are different. Therefore, we assumed that the transmissibility of $A_{1}$ is $K$ times that of $I_{1} \kappa$. The infection rate coefficients of $I_{1}$ and $A_{1}$ are $\beta_{1}$ and $\kappa \beta_{1}$, respectively.

3. We assumed that certain percentage $(1-p)$ $(0 \leq p \leq 1)$ of $E_{1}$ will transform into $I_{1}$ after an incubation period, while the other part $(p)$ of $E_{1}$ will become $A_{1}$ after a latent period. Hence, at time $t$, the development speed of $E_{1}$ to the $I_{1}$ pathway is proportional to the number of people in the incubation period, and the proportional coefficient is $(1-p) \omega_{1}$. The development speed of $E_{1}$ to the $A_{1}$ pathway is proportional to the number of people in the latent period, and the proportional coefficient is $p \omega_{1}$.

4. The out speed of the population in the $I_{1}$ and $A_{1}$ groups is respectively proportional to their population number, and the ratio coefficients are respectively $\gamma$ and $\gamma^{\prime}$.

5. The infectors of SFTS will produce antibodies after they are removed, but this study supposed that the $R_{1}$ will never be infected and that the $R_{1}$ is the destination of the transmission route between people, because literature on a second infection in the population was not found.

\section{Environment part of the MMDM}

In this part, $W$ represent the environmental transmission route in the MMDM, and this part was based on the following assumptions:

1. Although no literature strongly proved that the environment is one of the transmission route, some evidence suggested that the possibility of getting SFTS infection SFTS in the environment was higher than by ticks [30-33]. Hence, we assume that $W$ has the ability to facilitate the spread of SFTS to humans and animals. We set the transmissibility of $W$ to animals and human as $\beta_{w}$ [34].

2. As reported, the blood and excreta of infected human or host animals may diffuse the SFTSV. And as SFTS has commonly occurred extensively in the 
wild, we assumed that animals have the possibility to infect the environment by their blood or excreta. We set the propagation coefficient $j$ as 10 [35].

\section{Tick part of the MMDM}

In this part, the ticks were divided into susceptible ticks $\left(S_{2}\right)$, exposed ticks $\left(E_{2}\right)$ and asymptomatic ticks $\left(A_{2}\right)$. And this part of the MMDM was based on the following assumptions:

1. According to literature, SFTS mainly spreads by ticks $[1,19-21]$, and infected ticks can spread the virus by biting host animals or humans [36].

2. As the long-term storage host, ticks infected with SFTSV can preserve the pathogen and retain the infectious ability of the pathogen without symptoms [36]. So this study set the transmission route among ticks as the susceptible-exposed-asymptomatic (SEA) model.

3. In transmission among ticks, $A_{2}$ has transmissibility to infect ticks, and the infection rate coefficient is $\beta_{2}$, but our study considered that the SFTS was not diffused among ticks, so we set $\beta_{2}$ as 0 . And the $S_{2}$ will become $E_{2}$ by biting the infected animals and humans.

4. This study supposed that after one latent period, all the $E_{2}$ will transform to $A_{2}$. So at time $t$, the number of ticks in the $E_{2}$ to $A_{2}$ route is $\omega_{2} E_{2}$.

5. Ticks in the state of latent infection can infect host animals through biting. As the coefficient of infection rate of the virus spreading from ticks to a host animal is $\beta_{2-3}$, we denoted the part of host animal infection by a tick's bite as $\beta_{2-3} S_{3} A_{2}$. In addition, ticks can also spread SFTS among humans through direct bites. Since the coefficient of infection rate of the virus spreading from ticks to humans is $\beta_{2-1}$, the part of humans getting the virus by tick bites is denoted as $\beta_{2-1} S_{1} A_{2}$.

\section{Host animal part of the MMDM}

In this part, the animals were divided into susceptible animals $\left(S_{3}\right)$, exposed animals $\left(E_{3}\right)$ and asymptomatic animals $\left(A_{3}\right)$. The assumptions of this part in the MMDM were as follows:

1. According to reports by one study, the main amplification hosts of arboviruses are small rodents. This meant that arthropods can cause relative viremia by biting small rodents. However, other susceptible arthropods can also be infected and make the virus spread further by biting infected small rodents [37].

2. For SFTS, ticks infected with SFTSV can cause viremia by biting host animals. At the same time, susceptible ticks can also be infected by biting infected host animals [37-40]. Therefore, we still set the transmission progress of SFTSV as the SEA model in the host animal part of the transmission dynamics model.

3. Among the transmission of host animals, $A_{3}$ has transmissibility that can make $S_{3}$ transform to $E_{3}$ with the infection rate coefficient $\beta_{3}$. At the time $t$, the number of host animals in the $S_{3}$ to $E_{3}$ pathway was $\beta_{3} S_{3} \mathrm{~A}_{3}$.

4. This study supposed that all the $E_{3}$ will transform to $A_{3}$ after one latent period. At the time $t$, the number of host animals in the $E_{3}$ to $A_{3}$ pathway was $\omega_{3} E_{3}$.

5. The uninfected ticks can be infected after biting the host animal that is in a state of latent infection. The coefficient of host-to-tick transmission of the virus is $\beta_{3-2}$, so ticks with a $\beta_{3-2} S_{2} A_{3}$ component can acquire the virus by biting an infected host animal.

\section{The differential equation}

The above MMDM is expressed by the following differential equations:

$$
\begin{aligned}
\frac{d S_{1}}{d t}= & b_{r} N_{1}-d_{r} S_{1}-\beta_{1} S_{1}\left(I_{1}+k A_{1}\right) \\
& -\beta_{21} S_{1} A_{2}-\beta_{w} S_{1} I_{w}-\beta_{31} S_{1} A_{3} \\
\frac{d E_{1}}{d t}= & \beta_{1} S_{1}\left(I_{1}+k A_{1}\right)+\beta_{w} S_{1} I_{w}+\beta_{21} S_{1} A_{2} \\
& +\beta_{31} S_{1} A_{3}-d_{r} E_{1}-p \omega_{1} E_{1}-(1-p) \omega_{1} E_{1} \\
\frac{d A_{1}}{d t}= & p \omega_{1} E_{1}-d_{r} A_{1}-\gamma^{\prime} A_{1}
\end{aligned}
$$$$
\frac{d I_{1}}{d t}=(1-p) \omega_{1} E_{1}-\gamma I_{1}-\left(d_{r}+f\right) I_{1}
$$

$$
\frac{d R_{1}}{d t}=\gamma^{\prime} A_{1}+\gamma I_{1}-d_{r} R_{1}
$$

$$
\frac{d W}{d t}=j A_{3}
$$




$$
\begin{aligned}
& \frac{d S_{2}}{d t}=-\beta_{2} S_{2} A_{2}-\beta_{32} S_{2} A_{3} \\
& \frac{d E_{2}}{d t}=\beta_{2} S_{2} A_{2}+\beta_{32} S_{2} A_{3}-\omega_{2} E_{2} \\
& \frac{d A_{2}}{d t}=\omega_{2} E_{2} \\
& \frac{d S_{3}}{d t}=-\beta_{w} S_{3} W-\beta_{3} S_{3} A_{3}-\beta_{23} S_{3} A_{2} \\
& \frac{d E_{3}}{d t}=\beta_{3} S_{3} A_{3}+\beta_{23} S_{3} A_{2}+\beta_{w} S_{3} W-\omega_{3} E_{3} \\
& \frac{d A_{3}}{d t}=\omega_{3} E_{3}
\end{aligned}
$$

The left-hand side of the equation was respectively expressed as the instantaneous change velocity of $S, E, I$, $A$ and $R$ at time $t$.

\section{Estimation of parameters}

In our MMDM, there were a total of 20 parameters. The values of parameters $p, 1 / \omega_{1}, 1 / \gamma, 1 / \gamma, f, 1 / \omega_{2}, 1 / \omega_{3}$ and $j$ were all according to relative literatures. Among them, $p$ of recessive infection ranged from $3.2 \%$ to $5.5 \%$ [41], and the mean was $4.3 \%$ in this study, i.e., $p=0.043$. The $1 / \omega_{1}$ of the incubation period of SFTS in the population ranged from 9 to 14 days [42, 43], and the median was 11 days in this study. The course of the disease $1 / \gamma$ of overt infection was 2 weeks [44], i.e. 14 days. The research about the course of the disease $1 / \gamma^{\prime}$ of latent infection was not found, so we used the same days with the course of the disease of overt infection, i.e., 14 days. The fatality rate $f$ ranged from $11.2 \%$ to $30 \%$, and $f=0.16$ [5]. The incubation period after tick infection with SFTSV was $1 / \omega_{2}$ weeks, i.e., 7 days. The incubation period of SFTSV infection in host animals $1 / \omega_{3}$ was 12 days [39]. No valid data or literature support was found for the relative transmis-

\begin{tabular}{|c|c|c|c|c|}
\hline Parameter & Definition & Value & Unit & Method \\
\hline \multicolumn{5}{|l|}{ Person } \\
\hline$\beta_{1}$ & Person-to-person transmissibility coefficient & - & $\left(\text { Person* }^{*} \text { day }\right)^{-1}$ & Model fitting \\
\hline K & $\begin{array}{l}\text { Relative transmissibility coefficient of unapparent } \\
\text { infection }\end{array}$ & 1 & 1 & - \\
\hline$p$ & Proportion of latent infection & 0.043 & 1 & Ref. [41] \\
\hline $1 / \omega_{1}$ & Incubation period & 11 & Day & Ref. [42] \\
\hline $1 / \gamma$ & Infectious period of dominant infection & 14 & Day & Ref. [44] \\
\hline $1 / \gamma^{\prime}$ & Latent infection period & 14 & Day & - \\
\hline$f$ & Fatality rate & 0.16 & 1 & Ref. [5] \\
\hline$b r$ & Birth rate & 0.009481 & 1 & Statistical Yearbook of Jiangsu Province \\
\hline$d r$ & Mortality rate & 0.007003 & 1 & Statistical Yearbook of Jiangsu Province \\
\hline \multicolumn{5}{|l|}{ Ticks } \\
\hline$\beta_{2}$ & Coefficient of transmissibility between ticks & 0 & $\left(\right.$ Pieces* day $^{-1}$ & - \\
\hline$\beta_{2-1}$ & Coefficient of tick-to-human transmissibility & $8 \beta_{1}$ & $\left(\text { Person* }^{*} \text { day }\right)^{-1}$ & Ref. [34] \\
\hline$\beta_{2-3}$ & Coefficient of tick-to-host infection & $8 \beta_{1}$ & $\left(\text { Pieces }^{*} \text { day }\right)^{-1}$ & Ref. [34] \\
\hline $1 / \omega_{2}$ & Incubation period of ticks & 7 & Day & Ref. [26] \\
\hline \multicolumn{5}{|c|}{ Host animal } \\
\hline$\beta_{3}$ & Coefficient of transmissibility between host animal & $2 \beta_{1}$ & $\left(\text { Pieces }^{*} \text { day }\right)^{-1}$ & Ref. [34] \\
\hline$\beta_{3-1}$ & $\begin{array}{l}\text { Coefficient of transmissibility rate of host animal to } \\
\text { human }\end{array}$ & $2 \beta_{1}$ & $\left(\text { Pieces }^{*} \text { day }\right)^{-1}$ & Ref. [34] \\
\hline$\beta_{3-2}$ & Coefficient of host animal infection to ticks & $8 \beta_{1}$ & $\left(\text { Person }^{*} \text { day }\right)^{-1}$ & Ref. [34] \\
\hline $1 / \omega_{3}$ & Host animal incubation period & 12 & Day & Ref. [39] \\
\hline j & Rate of host animal discharge to the environment & 10 & - & Ref. [35] \\
\hline \multicolumn{5}{|c|}{ Environment } \\
\hline$\beta_{w}$ & $\begin{array}{l}\text { Coefficient of transmissibility rate of the environment } \\
\text { to humans and host animals }\end{array}$ & $9 \beta_{1}$ & (Human/animal*day) $^{-1}$ & Ref. [34] \\
\hline$W$ & Environmental tick density & 0.047494291 & One km²/person (flag hour) & Jiangsu Province surveillance data \\
\hline
\end{tabular}
sibility coefficient $\kappa$ of recessive infected persons. In this study, $k=1$ was selected for calculation. The $b r$ and $d r$ were obtained from the statistical yearbook of Jiangsu Province, see Table 1.

Table 1 Definition and value of parameters 
The coefficient of infection $\beta_{1}$ was generated by model fitting. The Runge-Kutta method of order 4 with tolerance set at 0.001 was used to perform curve fitting of the root mean square deviation between the data and best run so far. In this study, the seasonality of the transmission was considered. According to the MMDM, the seasonality should be dynamic, focusing on $\beta$. Therefore, a trigonometric function was adopted and shown as follows:

$$
\beta=\beta_{0}\left[1+\sin \left(\frac{2 \pi(t+\alpha)}{T}\right)\right]
$$

In the equation, $\beta_{0}, t, \alpha$ and $T$ refer to the baseline of the transmission relative, time, a constant which adjusts the position of time, and the time span of the season cycle, respectively.

\section{"Knock-out" simulation}

"Knock-out" simulation was performed as the reference [45] to quantify cutting different transmission routes. To "knock out" means to cut off the transmission routes between different groups. In the model study, the simulation sets a parameter to 0 and estimates the contribution of the parameter by calculating the number of reduced cases or the total attack rate. For example, in the MMDM, the contribution of environmental transmission $\beta_{w}$ was set to 0 , and its effect was reflected by calculating the number of reduced cases.

In this study, the transmissibility coefficient in the MMDM was used to reflect different transmission routes, including transmissibility of the environment to humans or host animals $\left(\beta_{w}\right)$, host animals to humans $\left(\beta_{3-1}\right)$, ticks to humans $\left(\beta_{2-1}\right)$, humans to humans $\left(\beta_{1}\right)$, ticks to host animals $\left(\beta_{2-3}\right)$, host animals to ticks $\left(\beta_{3-2}\right)$ and host animals to host animals $\left(\beta_{3}\right)$.

Based on the established SFTS transmissibility model, using 2019 data, a scenario of cutting off various transmission routes was established by setting one of the above infection rates up to seven values or to 0 at the time of simulation. We arranged the matrix between different transmission routes, as shown in Table 2, to perform a more comprehensive re-sectioning of transmission routes. There were seven scenarios at the same time:

Scenario 1: Only one coefficient $\beta$ was controlled to be zero.

we made $\beta_{w=0}$ or $\beta_{3-1=0}$ or $\beta_{2-1=0}$ or $\beta_{1=0}$ or $\beta_{2-3=0}$ or $\beta_{3-2=0}$ or $\beta_{3=0}$. At the same time, we kept the other six $\beta$ coefficients unchanged

Scenario 2: Two coefficients $\beta$ were controlled to be zero.

Then, we combined these seven coefficients $\beta$ in pairs so that two of them are equal to zero, while keeping the other five coefficients $\beta$ unchanged.

In the following scenarios, the method adopted was the same as the above two scenarios, that is, the $\beta$ value of the corresponding number was controlled to be zero, and the remaining $\beta$ values remain unchanged. Scenario 3: Three coefficients $\beta$ were controlled to be zero. Scenario 4: Four coefficients $\beta$ were controlled to be zero. Scenario 5: Five coefficients $\beta$ were controlled to be zero. Scenario 6: Six coefficients $\beta$ were controlled to be zero. Scenario 7: Seven coefficients $\beta$ were controlled to be zero.

The above methods were used to obtain the intervention effect of cutting off different transmission routes of SFTS. The indicators of intervention effect included: cumulative number of cases, total attack rate, peak incidence site and peak incidence. This was to provide guidance for the prevention and control of the occurrence of an SFTS epidemic.

\section{Effectiveness of interventions}

In this model, we only considered two interventions, and the model was established as shown in Fig. 3. We were trying to isolate the infections according to the transmission route of SFTS from person to person. In addition, although there are no targeted antiviral drugs to treat SFTS, drug treatment can still reduce the mortality rate and increase the clinical recovery rate. Therefore,

Table 2 Combined transmissibility matrix

\begin{tabular}{|c|c|c|c|c|c|c|c|}
\hline & $\beta_{1}$ & $\beta_{3}$ & $\beta_{w}$ & $\beta_{21}$ & $\beta_{31}$ & $\beta_{32}$ & $\beta_{23}$ \\
\hline$\beta_{1}$ & 1 & $2 \beta_{1}$ & $9 \beta_{1}$ & $8 \beta_{1}$ & $2 \beta_{1}$ & $8 \beta_{1}$ & $8 \beta_{1}$ \\
\hline$\beta_{3}$ & $1 / 2 \beta_{3}$ & 1 & $9 / 2 \beta_{3}$ & $4 \beta_{3}$ & $1 \beta_{3}$ & $4 \beta_{3}$ & $4 \beta_{3}$ \\
\hline$\beta_{w}$ & $1 / 9 \beta_{w}$ & $2 / 9 \beta_{w}$ & 1 & $8 / 9 \beta_{w}$ & $2 / 9 \beta_{w}$ & $8 / 9 \beta_{w}$ & $8 / 9 \beta_{w}$ \\
\hline$\beta_{21}$ & $1 / 8 \beta_{21}$ & $1 / 4 \beta_{21}$ & $9 / 8 \beta_{21}$ & 1 & $1 / 4 \beta_{21}$ & $1 \beta_{21}$ & $1 \beta_{21}$ \\
\hline$\beta_{31}$ & $1 / 2 \beta_{31}$ & $1 \beta_{31}$ & $9 / 2 \beta_{31}$ & $4 \beta_{31}$ & 1 & $4 \beta_{31}$ & $4 \beta_{31}$ \\
\hline$\beta_{32}$ & $1 / 8 \beta_{32}$ & $1 / 4 \beta_{32}$ & $9 / 8 \beta_{32}$ & $1 \beta_{32}$ & $1 / 4 \beta_{32}$ & 1 & $1 \beta_{32}$ \\
\hline$\beta_{23}$ & $1 / 8 \beta_{23}$ & $1 / 4 \beta_{23}$ & $9 / 8 \beta_{23}$ & $1 \beta_{23}$ & $1 / 4 \beta_{23}$ & $1 \beta_{23}$ & 1 \\
\hline
\end{tabular}




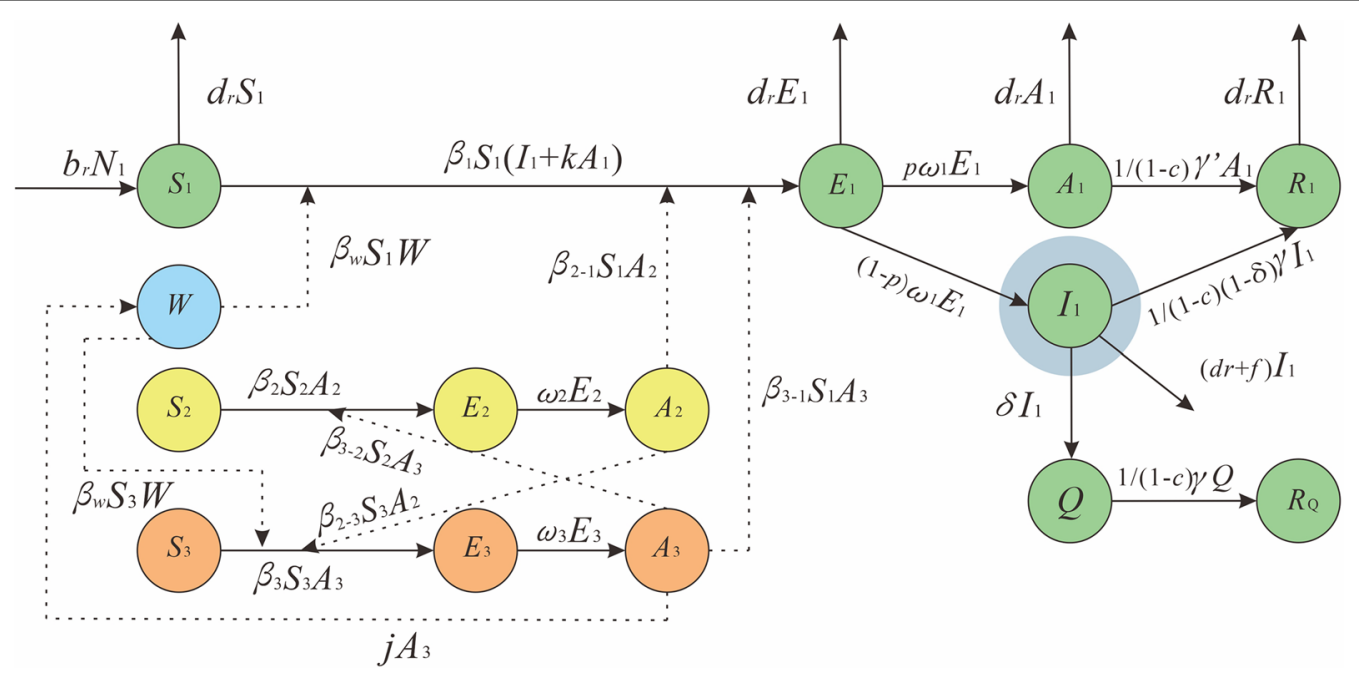

Fig. 3 Flowchart of the MMDM with interventions

considering interventions that can shorten the course of the disease, such as hospitalization or drug treatment, was important $[46,47]$.

For the isolation, $Q$ was the number of people isolated, $R_{Q}$ was the recovery of isolation, $\delta$ was the isolation coefficient and $c$ was the coefficient of shortening the disease course in the model. We set the $\phi$ as the proportion of isolation which can be calculated by $\phi=\frac{R_{Q}}{R_{1}+R_{Q}}$; we then set $\phi$ as $98 \%, 90 \%, 80 \%, 70 \%, 60 \%$ and $50 \%$ to simulate the solo effect of different isolation ratios.

For the intervention to shorten the disease courses, we used $\gamma$ to represent this intervention. We set $\gamma$ as $1 / 14,1 / 12,1 / 10,1 / 8,1 / 6$ and $1 / 4$ to simulate the solo effect of shortening different days.

We did not know how many isolated cases and how many days of medication would shorten the course of the disease. Therefore, we set $\phi$ as $0.5 \%, 5 \%$ and $50 \%$, and set $\gamma$ as $1 / 14,1 / 12,1 / 10,1 / 8,1 / 6$ and $1 / 4$ to simulate the combined effect of SFTS under different intervention intensity.

The indicators of intervention effect included: cumulative number of cases, incidence rate, peak position of incidence and peak size of incidence. Finally, the model provided the optimal way to intervene in the spread of SFTS and provided guidance for the prevention and control of the outbreak of SFTS.

\section{Model simulation and statistical analysis}

In this study, Excel was used for data summary and chart drawing, IBM SPSS Statistics (version 21.0.0.0) was used for data statistical analysis, Berkeley Madonna (Version 8.3.18) was used for fitting existing data and models, and epidemic prediction and evaluation were conducted for intervention effects under different transmission routes.

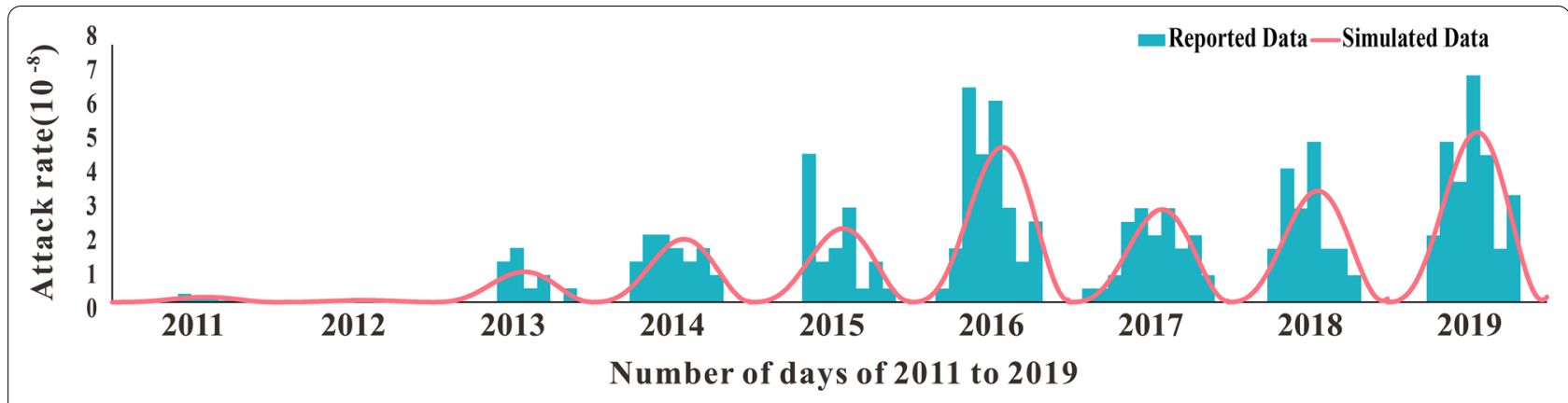

Fig. 4 Model fitting results of the model to the reported SFTS incidence data from 2011 to 2019 in Jiangsu Province, China 


\section{Results}

\section{Model fitting}

The result of model fitting using 2011-2019 SFTS incidence rates in Jiangsu Province was shown in Fig. 4. By analyzing every month's and year's SFTS incidence rates, we discovered that the incidence rate of SFTS strictly changed seasonally. This meant that in a year, the incidence rate was high in summer and autumn with two peaks, and lowered with no cases in winter. Therefore, the seasonal correction function was added to carry on fitting in the model. Just like the results of our model fitting, the SFTS incidence rate of 2011-2019 in Jiangsu Province was periodically changed. It is often at rest in winter, begins to increase in spring and peaks by JulyAugust. Notably, the peak incidence rate of SFTS in Jiangsu Province has increased to some extent in recent years compared with 2011-2014. The $R^{2}$ and $P$ values of the model fitting results for 2011-2019 are listed in Table 3 . The model fitting results for all years were good, and $P$ was significant $(P<0.05)$.

\section{Model simulation of cutting transmission routes}

Table 4 showed the simulation results of truncating different transmission routes based on the SFTS transmission dynamics model in Jiangsu Province in 2019. In general, when the cut transmission route has no effect, the cumulative number of cases was 671 , and the peak time was 205 days.

We mainly studied the spread of SFTS in the population. When the transmission route between people $\beta_{1}$ was cut off, SFTS cannot be transmitted in the population. With zero cases, the model cannot continue to simulate, and hence, other combinations containing $\beta_{1}$ were not shown. When cutting off a single transmission route, it is worth noting that when the environmental transmission $\beta_{w}$ was cut off alone, the number of cases also became zero. None of the other transmission routes cut off alone reduced the number of SFTS

Table 3 Model fitting result of 2011-2019

\begin{tabular}{lll}
\hline Year & $R^{2}$ & $P$ \\
\hline 2011 & 0.573878 & $<0.05$ \\
2012 & 0.299520 & $<0.05$ \\
2013 & 0.482155 & $<0.05$ \\
2014 & 0.764983 & $<0.05$ \\
2015 & 0.408163 & $<0.05$ \\
2016 & 0.767604 & $<0.05$ \\
2017 & 0.776788 & $<0.05$ \\
2018 & 0.801787 & $<0.05$ \\
2019 & 0.758567 & $<0.05$ \\
\hline
\end{tabular}

infections. When two transmission routes, such as a combination with environmental transmission were cut off, the number of patients was also reduced. When the environmental transmission $\beta_{w}$ and animals-to-humans transmission $\beta_{31}$ were cut off together, the peak time of disease was advanced to 10 days. When other combinations that can cause a decrease in SFTS cases were cut off, the peak time was advanced to 198 days. When three transmission routes (such as the combination of environmental transmission $\beta_{w}$, animals-to-humans transmission $\beta_{31}$ and ticks-to-humans transmission $\beta_{21}$ ) were cut off at the same time, the number of cases decreased significantly. And similarly, as above, when $\beta_{31}$ and $\beta_{\mathrm{w}}$ were cut off, the peak time was advanced to 10 days. With a cut-off of environmental transmission $\beta_{w}$ and animals-toticks transmission $\beta_{32}$, ticks-to-animals transmission $\beta_{23}$ and ticks-to-humans transmission $\beta_{21}$ at the same time, the peak time was also increased to 198 days. When four transmission routes were cut off at the same time (such as $\beta_{3}, \beta_{w}, \beta_{21}$ and $\left.\beta_{31}\right)$, the peak time of SFTS was advanced to 7 days. The remaining results were the same as above. When five and six transmission routes were cut off at the same time, SFTS only occurred when environmental transmission was not cut off, and the peak onset time was not advanced. For more details, see Table 4.

\section{Taking different interventions}

In the study of separate interventions, the shortening of the disease course was assumed to be no shortening and shortening of 2 days, 4 days, 6 days, 8 days and 10 days; the isolation ratio was assumed to be: $98 \%, 90 \%$, $80 \%, 70 \%, 60 \%$ and $50 \%$. When studying the combined effects of the two interventions, the isolation ratios were assumed to be $0.5 \%, 5 \%$ and $50 \%$. It turned out that when a separate intervention was implemented alone, shortening the course of the disease will not limit the spread of fever with thrombocytopenia syndrome. But when the quarantine was implemented, only one case was reduced. When the joint intervention was implemented (i.e., the course of the disease was not shortened and the isolation ratio was $5 \%$ and $50 \%$ ), only one case was reduced. Therefore, these two interventions had little effect on the number of cases of fever with thrombocytopenia syndrome, as shown in Tables 5 and 6 .

\section{Discussion}

SFTS is an emerging infectious disease caused by SFTSV. Recently, the incidence rate has been increasing year by year, and the coverage of the epidemic area has expanded. Jiangsu Province is one of the provinces with the highest incidence of SFTS, and they have conducted stringent SFTS monitoring. This study was established to use a model based on the SFTS monitoring data of Jiangsu 
Chang et al. Parasites Vectors

(2021) 14:237

Page 10 of 15

Table 4 Interventional effect of cutting off different transmission routes on SFTS

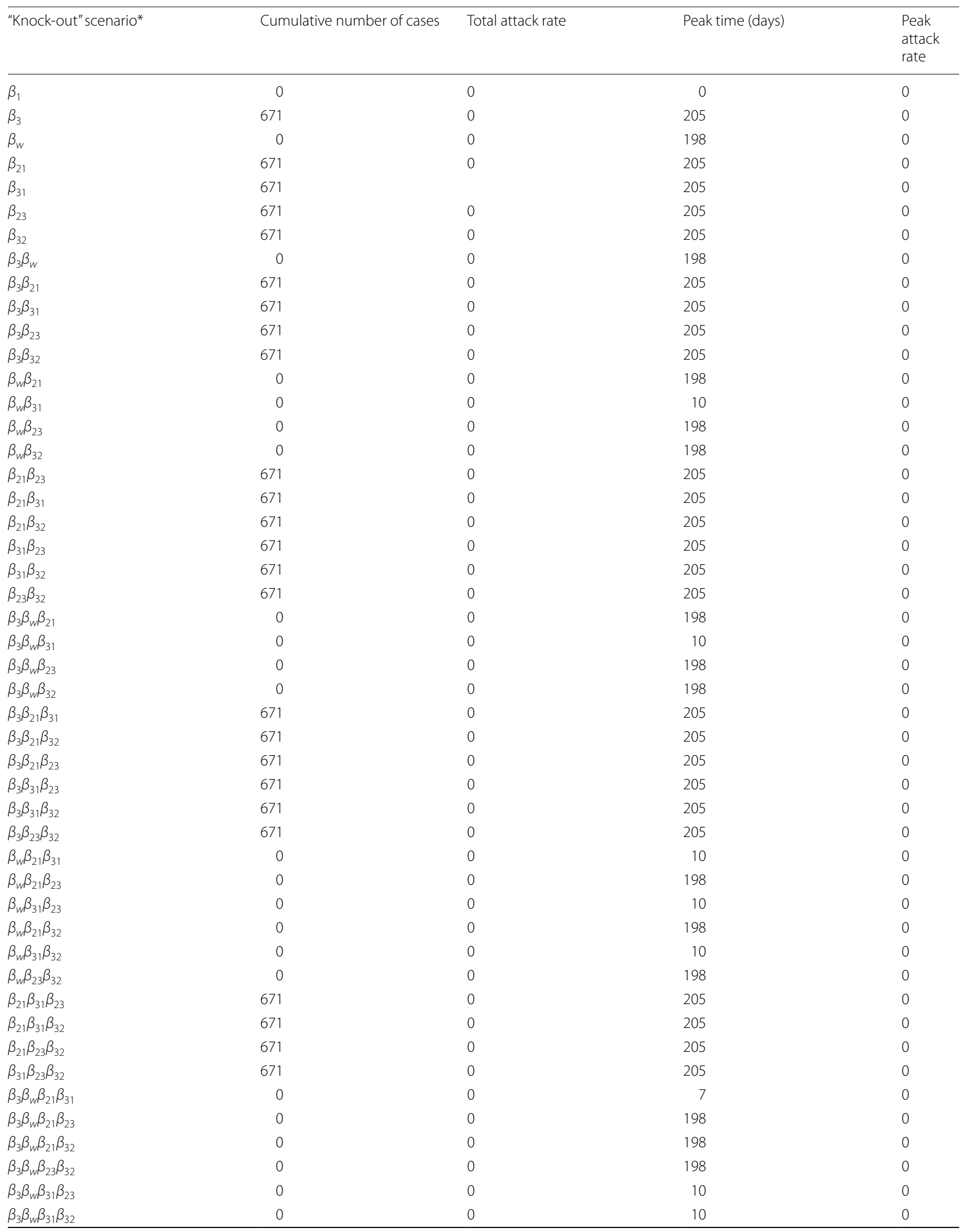


Table 4 (continued)

\begin{tabular}{|c|c|c|c|c|}
\hline "Knock-out"scenario* & Cumulative number of cases & Total attack rate & Peak time (days) & $\begin{array}{l}\text { Peak } \\
\text { attack } \\
\text { rate }\end{array}$ \\
\hline$\beta_{3} \beta_{21} \beta_{31} \beta_{23}$ & 671 & 0 & 205 & 0 \\
\hline$\beta_{3} \beta_{21} \beta_{23} \beta_{32}$ & 671 & 0 & 205 & 0 \\
\hline$\beta_{3} \beta_{21} \beta_{31} \beta_{32}$ & 671 & 0 & 205 & 0 \\
\hline$\beta_{3} \beta_{31} \beta_{23} \beta_{32}$ & 671 & 0 & 205 & 0 \\
\hline$\beta_{w} \beta_{21} \beta_{31} \beta_{23}$ & 0 & 0 & 10 & 0 \\
\hline$\beta_{w} \beta_{21} \beta_{31} \beta_{32}$ & 0 & 0 & 10 & 0 \\
\hline$\beta_{w} \beta_{21} \beta_{23} \beta_{32}$ & 0 & 0 & 198 & 0 \\
\hline$\beta_{w} \beta_{31} \beta_{23} \beta_{32}$ & 0 & 0 & 10 & 0 \\
\hline$\beta_{21} \beta_{31} \beta_{23} \beta_{32}$ & 671 & 0 & 205 & 0 \\
\hline$\beta_{3} \beta_{w} \beta_{21} \beta_{31} \beta_{23}$ & 0 & 0 & 10 & 0 \\
\hline$\beta_{3} \beta_{w} \beta_{21} \beta_{31} \beta_{32}$ & 0 & 0 & 10 & 0 \\
\hline$\beta_{3} \beta_{w} \beta_{21} \beta_{23} \beta_{32}$ & 0 & 0 & 198 & 0 \\
\hline$\beta_{3} \beta_{w} \beta_{31} \beta_{23} \beta_{32}$ & 0 & 0 & 10 & 0 \\
\hline$\beta_{3} \beta_{21} \beta_{31} \beta_{23} \beta_{32}$ & 671 & 0 & 205 & 0 \\
\hline$\beta_{w} \beta_{21} \beta_{31} \beta_{23} \beta_{32}$ & 0 & 0 & 10 & 0 \\
\hline$\beta_{3} \beta_{w} \beta_{21} \beta_{31} \beta_{23} \beta_{32}$ & 0 & 0 & 10 & 0 \\
\hline
\end{tabular}

"Knock-out" means to simulate cutting off the transmission routes by setting a parameter to 0 , and estimates the contribution of the parameter by calculating the number of reduced cases or the total attack rate. The different scenario means which parameter was set as 0

Table 5 Interventional effect of taking joint interventions

\begin{tabular}{|c|c|c|c|c|}
\hline Intervention & Cumulative number of cases & Total attack rate & Peak time (days) & $\begin{array}{l}\text { Peak } \\
\text { attack } \\
\text { rate }\end{array}$ \\
\hline$\gamma=1 / 14+\emptyset=0$ & 530 & 0.00 & 197 & 0 \\
\hline$\gamma=1 / 14+\emptyset=0.5 \%$ & 531 & 0.00 & 197 & 0 \\
\hline$\gamma=1 / 14+\emptyset=5 \%$ & 530 & 0.00 & 197 & 0 \\
\hline$\gamma=1 / 14+\emptyset=50 \%$ & 530 & 0.00 & 197 & 0 \\
\hline$\gamma=1 / 12+\emptyset=0$ & 531 & 0.00 & 197 & 0 \\
\hline$\gamma=1 / 12+\emptyset=0.5 \%$ & 531 & 0.00 & 197 & 0 \\
\hline$\gamma=1 / 12+\emptyset=5 \%$ & 531 & 0.00 & 197 & 0 \\
\hline$\gamma=1 / 12+\emptyset=50 \%$ & 531 & 0.00 & 197 & 0 \\
\hline$\gamma=1 / 10+\emptyset=0$ & 531 & 0.00 & 197 & 0 \\
\hline$\gamma=1 / 10+\emptyset=0.5 \%$ & 531 & 0.00 & 197 & 0 \\
\hline$\gamma=1 / 10+\emptyset=5 \%$ & 531 & 0.00 & 197 & 0 \\
\hline$\gamma=1 / 10+\emptyset=50 \%$ & 531 & 0.00 & 197 & 0 \\
\hline$\gamma=1 / 8+\emptyset=0$ & 531 & 0.00 & 197 & 0 \\
\hline$\gamma=1 / 8+\emptyset=0.5 \%$ & 531 & 0.00 & 197 & 0 \\
\hline$\gamma=1 / 8+\emptyset=5 \%$ & 531 & 0.00 & 197 & 0 \\
\hline$\gamma=1 / 8+\emptyset=50 \%$ & 531 & 0.00 & 197 & 0 \\
\hline$\gamma=1 / 6+\emptyset=0$ & 531 & 0.00 & 197 & 0 \\
\hline$\gamma=1 / 6+\emptyset=0.5 \%$ & 531 & 0.00 & 197 & 0 \\
\hline$\gamma=1 / 6+\emptyset=5 \%$ & 531 & 0.00 & 197 & 0 \\
\hline$\gamma=1 / 6+\emptyset=50 \%$ & 531 & 0.00 & 197 & 0 \\
\hline$\gamma=1 / 4+\emptyset=0$ & 531 & 0.00 & 197 & 0 \\
\hline$\gamma=1 / 4+\emptyset=0.5 \%$ & 531 & 0.00 & 197 & 0 \\
\hline$\gamma=1 / 4+\emptyset=5 \%$ & 531 & 0.00 & 197 & 0 \\
\hline$\gamma=1 / 4+\emptyset=50 \%$ & 531 & 0.00 & 197 & 0 \\
\hline
\end{tabular}

${ }^{\mathrm{a}} \gamma$ represent the intervention of shorten disease course and $\varphi$ represent the proportion of isolation 
Table 6 Interventional effect of taking isolation

\begin{tabular}{lllll}
\hline Isolation ratio & Cumulative number of cases & Cumulative attack rate & Peak time (days) & Peak attack rate \\
\hline $50 \%$ & 530 & 0.00 & 201 & 0.00 \\
$60 \%$ & 530 & 0.00 & 201 & 0.00 \\
$70 \%$ & 530 & 0.00 & 201 & 0.00 \\
$80 \%$ & 530 & 0.00 & 201 & 0.00 \\
$90 \%$ & 530 & 0.00 & 201 & 0.00 \\
$98 \%$ & 530 & 0.00 & 201 & 0.00 \\
\hline
\end{tabular}

Province from 2011 to 2019. The SFTS transmission dynamics model was used to simulate the change in incidence rate by cutting different transmission routes, and taking interventions into consideration and assessing the effect of those interventions.

\section{The effect of knock-out simulation}

Previous studies have shown that the number of SFTS patients infected by the environment were more than those who were infected by ticks [19, 30-33]. But most studies only use the density of ticks in the environment and the antibody of SFTSV in ticks to evaluate the hazardous situation of the environment [22, 48-50], so they did not consider the environment as one of the transmission route. As we all know, several factors such as the number of ticks, the dominant phase of ticks, outdoor activities and the change of weather can affect the occurrence of SFTS [51]. There was one study that collected SFTSV from inanimate objects in the room of SFTS patients. Thus, the environment could be considered as one of the transmission routes of SFTS, although a test result of the air sample was negative [52]. Therefore, based on the literature and the 2019 data of SFTS incidents in Jiangsu Province, we established the SFTS transmission dynamics model and used the coefficient of transmissibility to reflect the different routes of transmission. We simulated cutting different transmission routes to show the different effects of interventions. The result of this study showed that in all the combinations of cutting different transmission routes, the cumulative number of SFTS cases and other indicators could be significantly reduced when the transmission route containing the environment was cut off. Moreover, the intervention effect was more obvious when the environmental and host animal transmission routes were cut simultaneously. Those results indicated that the environment is an important route for the transmission of SFTS, and this was consistent with findings of previous research. Besides, this also provided a direction that can be explained as follows. It is possible that people were not exposed to a wild environment, and the chance of contacting ticks or animal excreta, blood, etc. decreased and accounted for the low SFTS incidence rate. In addition, some literatures have shown that SFTS was an environment-tick-host animal-tick cycle and that humans were infected by accidental participation in one of the steps. Therefore, the more transmission ways cut off, the smaller the impact of SFTS was. Interestingly, the effect of cutting off the environment and the transmission route of ticks on SFTS was less than that of cutting off the environment and host animals simultaneously. This might be the main way for people to be infected with SFTS except for tick bites. In previous studies, there were also literatures showing that those infected with SFTS with a clear history of tick bites only accounted for a small proportion (about 22-29\% [6, 33, 53]) of all infected individuals. The study also suggested that humans might be infected with SFTS after exposure to animal blood [6]. Although the transmission of SFTS was initiated by ticks, it may be that the two transmission routes of animal and environment are more important for human beings.

\section{The effect of taking interventions}

For infectious diseases, there are three links and two factors. The three links are: the source of infection, transmission routes and the population. The two factors include natural factors and social factors. Common measures to control infectious diseases include controlling the source of infection, cutting off the route of transmission and protecting the population. Therefore, after cutting off the route of transmission and protecting the population, there is still a need to control the source of infection. In that regard, we chose to take interventions including taking isolation and shortening the course of the disease. We also assessed the effects of taking isolation and shortening the course of the disease according to the established SFTS transmissibility model. Based on the data of SFTS, the results of the simulation were used to evaluate the effect of the two interventions on SFTS. The results showed that whether implementing isolation alone or shortening the course of the disease, or combining the two interventions, the effect of interventions 
mentioned above on the incidence of SFTS was limited. And the different isolation ratio had little effect on the cases. This may be because that the incidence of SFTS is low. People living in cities were less likely to be infected with SFTSV as most of the patients are farmers or field workers [19, 32, 33, 51]. Even with humans-to-humans transmission, the greatest chance of occurrence was only among members of the population who come in contact with blood, such as nurses or family members [54]. In addition, secondary SFTS infection leads to milder clinical manifestations compared with primary SFTS. Therefore, secondarily infected patients only experience sudden fever, thrombocytopenia, leukopenia and gastrointestinal symptoms and recover more quickly [55].

In summary, implementing isolation and shortening the course of the disease had little impact on SFTS. This may suggested that prevention and control of the development of SFTS should focus on cutting off the direction of transmission routes. Therefore, according to the results of cutting off the transmission route earlier, interventions to prevent the transmission of SFTS suggest the following several aspects: First, for the environment, a long stay in the wild environment should be avoided. Also, residential areas should be cleaned/sanitized regularly and field working personnel should be equipped with protective clothing and gear such as insect repellents. Secondly, regarding tick transmission, regular repellent work should be done in rural and suburban areas to prevent tick breeding. Third, for animal transmission, the poultry and other domesticated animals should be well protected in rural areas to avoid the livestock being bitten by infected wild animals. At the same time, the livestock should be regularly treated with insecticide, physically examined for ticks and their serum should be tested regularly for SFTSV. Finally, for human-to-human transmission, medical staff and patients' families should protect themselves when handling SFTS cases and avoid direct contact with the patient's body or blood. Hospitals and township health centers in high-risk areas should be equipped with corresponding protective gear for use. Additionally, as our research results showed that isolation of SFTS patients or shortening the course of the disease cannot reduce the spread of SFTS, we should reduce the formulation of such plans to avoid wasting resources.

\section{Limitations}

There were some limitations in our study: first, the data of SFTS cases collected by the China Information Network System of Disease Prevention and Control. Since the capability and availability of this system was finite, our findings need to be interpreted with caution. Second, this study failed to separate the effects of ticks and host animals on humans in the environment. Third, some parameters of our model were collected from literature that may represent certain error in terms of timeliness.

\section{Conclusions}

In this study, the transmission dynamics model of SFTS was constructed based on the epidemiological characteristics of SFTS in Jiangsu Province. The effects of cutting off different transmission routes and taking isolation and shortening the course of the disease on SFTS control were evaluated. Finally, it was determined that cutting off the transmission route from the environment to humans had the greatest effect on SFTS prevention and control.

\section{Abbreviations \\ SFTS: Severe fever with thrombocytopenia syndrome; SFTSV: Severe fever with thrombocytopenia syndrome virus; SEIAR: Susceptible-exposed-infectious- asymptomatic-recovered; MMDM: Multi-population and multi-route dynamic model; SEA: Susceptible-exposed-asymptomatic; CDC: Centers for Disease Control and Prevention.}

\section{Supplementary Information}

The online version contains supplementary material available at https://doi. org/10.1186/s13071-021-04732-3.

Additional file 1: Figure S1. The location of Jiangsu Province in China.

\section{Acknowledgements \\ We thank the staff members at the hospitals, local health departments and municipal- and county-level Centers for Disease Control and Preven- tion offices for their valuable assistance in coordinating the data collection. We would like to thank Gifty Marley of Nanjing Medical University for her help with editing.}

\section{Authors' contributions}

TMC, JR and BD designed the research; NZ, JR, BD, CL, JFH, ZYL, WKL, LL, PHL, TLY and XQC analyzed data; TMC, JR, BD, LXQ, ZYZ, SNL, MY, YZZ, YW, JWX, JFH, $Z Y L, Z F L, S Y L$ and JLH conducted the research and analyzed the results; TMC, $J \mathrm{LH}, \mathrm{NZ}$, JR and BD wrote the manuscript. All authors read and approved the final manuscript.

\section{Funding}

This work was partly supported by the Bill \& Melinda Gates Foundation (INV-005834), the Science and Technology Program of Fujian Province (no. 2020Y0002) and the Xiamen New Coronavirus Prevention and Control Emergency Tackling Special Topic Program (no. 3502Z2020YJ03); Natural Science Foundation of China (JL Hu: no. 81601794; ZF Li: no. 81703284), Jiangsu Provincial Natural Science Foundation (ZF Li: no. BK20161584) and "Six One Project"Top Talent Research Plan of Jiangsu High Level Health Talents (J Hu: LGY2019073).

Availability of data and materials

Data supporting the conclusions of this article are included within the article.

\section{Declarations}

Ethics approval and consent to participate

This effort of disease control was part of CDC's routine responsibility in Jiangsu Province, China. Therefore, institutional review and informed consent were not required for this study. All data analyzed were anonymized. 


\section{Consent for publication}

Not applicable.

\section{Competing interests}

The authors declare that they have no competing interests.

Received: 10 December 2020 Accepted: 21 April 2021 Published online: 06 May 2021

\section{References}

1. Yu XJ, Liang MF, Zhang SY, Liu Y, Li JD, Sun YL, et al. Fever with thrombocytopenia associated with a novel bunyavirus in China. N Engl J Med. 2011;364(16):1523-32. https://doi.org/10.1056/NEJMoa1010095.

2. Gong L, Wang J, Zhang Y, Zhang L, Lyu Y, Ma W, et al. Socioeconomic burden of severe fever with thrombocytopenia syndrome in endemic areas of Anhui Province, eastern China. Zoonoses Public Health. 2019;66(7):879-85. https://doi.org/10.1111/zph.12634.

3. Zhan JB, Cheng J, Hu B, Li J, Pan RG, Yang ZH, et al. Pathogens and epidemiologic feature of severe fever with thrombocytopenia syndrome in Hubei province, China. Virus Res. 2017;232:63-8. https://doi.org/10.1016/j. virusres.2017.01.009.

4. Li H, Lu OB, Xing B, Zhang SF, Liu K, Du J, et al. Epidemiological and clinical features of laboratory-diagnosed severe fever with thrombocytopenia syndrome in China, 2011-17: a prospective observational study. Lancet Infect Dis. 2018;18(10):1127-37. https://doi.org/10.1016/S1473-3099(18) 30293-7.

5. Wang L, Wan G, Shen Y, Zhao ZH, Lin L, Zhang W, et al. A nomogram to predict mortality in patients with severe fever with thrombocytopenia syndrome at the early stage-A multicenter study in China. Plos Neglect Trop D. 2019;13:11. https://doi.org/10.1371/journal.pntd.0007829.

6. Li DX. Severe fever with thrombocytopenia syndrome: a newly discovered emerging infectious disease. Clin Microbiol Infec. 2015;21(7):614-20. https://doi.org/10.1016/j.cmi.2015.03.001.

7. Li ZF, Hu JL, Cui LBA, Hong Y, Liu JW, Li PF, et al. Increased prevalence of severe fever with thrombocytopenia syndrome in eastern china clustered with multiple genotypes and reasserted virus during 2010-2015. Sci Rep Uk. 2017. https://doi.org/10.1038/s41598-017-06853-1.

8. Silvas JA, Aguilar PV. The emergence of severe fever with thrombocytopenia syndrome virus. Am J Trop Med Hyg. 2017;97(4):992-6. https://doi. org/10.4269/ajtmh.16-0967.

9. Im JH, Baek J, Durey A, Kwon HY, Chung MH, Lee JS. Current status of tick-borne diseases in South Korea. Vector Borne Zoonotic Dis. 2019;19(4):225-33. https://doi.org/10.1089/vbz.2018.2298.

10. Kimura T, Fukuma A, Shimojima M, Yamashita Y, Mizota F, Yamashita M, et al. Seroprevalence of severe fever with thrombocytopenia syndrome (SFTS) virus antibodies in humans and animals in Ehime prefecture, Japan, an endemic region of SFTS. J Infect Chemother. 2018;24(10):802-6. https://doi.org/10.1016/j.jiac.2018.06.007.

11. Zhan JB, Wang Q, Cheng J, Hu B, Li J, Zhan FX, et al. Current status of severe fever with thrombocytopenia syndrome in China. Virol Sin. 2017:32(1):51-62. https://doi.org/10.1007/s12250-016-3931-1.

12. Gai ZT, Liang MG, Zhang Y, Zhang S, Jin C, Wang SW, et al. Person-toperson transmission of severe fever with thrombocytopenia syndrome bunyavirus through blood contact. Clin Infect Dis. 2012;54(2):249-52. https://doi.org/10.1093/cid/cir776.

13. Liang S, Bao C, Zhou M, Hu J, Tang F, Guo X, et al. Seroprevalence and risk factors for severe fever with thrombocytopenia syndrome virus infection in Jiangsu Province, China, 2011. Am J Trop Med Hyg. 2014;90(2):256-9. https://doi.org/10.4269/ajtmh.13-0423.

14. Zhang D, Sun C, Yu H, Li J, Liu W, Li Z, et al. Environmental risk factors and geographic distribution of severe fever with thrombocytopenia syndrome in Jiangsu Province, China. Vector Borne Zoonotic Dis. 2019;19(10):758-66. https://doi.org/10.1089/vbz.2018.2425.

15. Chun YCN, Bing-jun W, Wei L, Lan Z. Clinical analysis of 253 patients with severe fever with thrombocytopenia syndrome. China J Modern Med. 2011;3413-7.

16. Shu-Jun DLY, Xiao-mei Z, Xian-Jun W, Xue-Jie Y. Research advances on epidemiology of severe fever with thrombocytopenia syndrome. Chin J Zoonoses. 2014. https://doi.org/10.3969/cjz.j.issn.
17. Liu W, Lu QB, Cui N, Li H, Wang LY, Liu K, et al. Case-fatality ratio and effectiveness of ribavirin therapy among hospitalized patients in China who had severe fever with thrombocytopenia syndrome. Clin Infect Dis. 2013;57(9):1292-9. https://doi.org/10.1093/cid/cit530.

18. Ai-guo YJ-h, Du Yan-hua, Wang Hai-feng, Tang Xiao-yan, Chen Haomin, Xu Bian-li. Research advances on epidemiology of severe fever with thrombocytopenia syndrome Analysis of the epidemiological and pathogenic characteristics of severe fever with thrombocytopenia syndrome (SFTS) in Henan Province of China, 2012-2013. J Pathogen Biol 2014:552-5

19. Li DX. A highly pathogenic new bunyavirus emerged in China. Emerg Microbes Infec. 2013. https://doi.org/10.1038/emi.2013.1.

20. Zhang YZ, Zhou DJ, Xiong Y, Chen XP, He YW, Sun Q, et al. Hemorrhagic fever caused by a novel tick-borne Bunyavirus in Huaiyangshan, China. Zhonghua Liu Xing Bing Xue Za Zhi. 2011;32(3):209-20.

21. Zhang YZ, Zhou DJ, Qin XC, Tian JH, Xiong YW, Wang JB, et al. The ecology, genetic diversity, and phylogeny of huaiyangshan virus in China. J Virol. 2012;86(5):2864-8. https://doi.org/10.1128/Jvi.06192-11.

22. Kim-Jeon MD, Jegal S, Jun H, Jung H, Park SH, Ahn SK, et al. Four year surveillance of the vector hard ticks for SFTS, Ganghwa-do, Republic of Korea. Korean J Parasitol. 2019;57(6):691-8. https://doi.org/10.3347/kjp. 2019.57.6.691.

23. Klompen JSH, Black WC, Keirans JE, Oliver JH. Evolution of ticks. Annu Rev Entomol. 1996;41:141-61. https://doi.org/10.1146/annurev.en.41.010196. 001041.

24. Liu $Y$, Huang $X Y$, Du YH. Survey on ticks and detection of new bunyavirus in some vect in the endemic areas of fever, thrombocytopenia and leukopenia syndrome (FTLS) in Henan province. Chin J Preventive Med. 2012:46:500-4.

25. Yamaji K, Aonuma H, Kanuka H. Distribution of tick-borne diseases in Japan: past patterns and implications for the future. J Infect Chemother. 2018;24(7):499-504. https://doi.org/10.1016/j.jiac.2018.03.012.

26. Hu J, Li Z, Cai J, Liu D, Zhang X, Jiang R, et al. A cluster of bunyavirusassociated severe fever with thrombocytopenia syndrome cases in a coastal plain area in China, 2015: identification of a previously unidentified endemic region for severe fever with thrombocytopenia bunyavirus. Open Forum Infect Dis. 2019;6(6):209. https://doi.org/10.1093/ofid/ ofz209.

27. Li Z, Hu J, Bao C, Li P, Qi X, Qin Y, et al. Seroprevalence of antibodies against SFTS virus infection in farmers and animals, Jiangsu, China. J Clin Virol. 2014;60(3):185-9. https://doi.org/10.1016/j.jcv.2014.03.020.

28. Li Z, Hu J, Cui L, Hong Y, Liu J, Li P, et al. Increased prevalence of severe fever with thrombocytopenia syndrome in Eastern China clustered with multiple genotypes and reasserted virus during 2010-2015. Sci Rep. 2017;7(1):6503. https://doi.org/10.1038/s41598-017-06853-1.

29. Wang YL, Deng BC, Zhang J, Cui W, Yao WQ, Liu P. Person-to-person asymptomatic infection of severe fever with thrombocytopenia syndrome virus through blood contact. Internal Med. 2014;53(8):903-6. https://doi.org/10.2169/internalmedicine.53.1164.

30. Ding F, Guan XH, Kang K, Ding SJ, Huang LY, Xing XS, et al. Risk factors for bunyavirus-associated severe fever with thrombocytopenia syndrome, China. Plos Neglect Trop D. 2014;8:10. https://doi.org/10.1371/journal. pntd.0003267.

31. Ding F, Zhang WY, Wang LY, Hu WB, Magalhaes RJS, Sun HL, et al. Epidemiologic features of severe fever with thrombocytopenia syndrome in China, 2011-2012. Clin Infect Dis. 2013;56(11):1682-3. https://doi.org/10. 1093/cid/cit100.

32. Liu K, Zhou H, Sun RX, Yao HW, Li Y, Wang LP, et al. A national assessment of the epidemiology of severe fever with thrombocytopenia syndrome, China. Sci Rep Uk. 2015. https://doi.org/10.1038/srep09679.

33. Sun JM, Chai CL, Lv HK, Lin JF, Wang CW, Chen EF, et al. Epidemiological characteristics of severe fever with thrombocytopenia syndrome in Zhejiang Province, China. Int J Infect Dis. 2014;25:180-5. https://doi.org/ 10.1016/j.ijid.2014.02.022

34. Zhang $\mathrm{H}$. Epidemiological characteristics of febrile thrombocytopenia syndrome. Chin J Thrombosis Hemostasis. 2019. https://doi.org/10.3969/j. issn.1009-6213.2019.02.033.

35. Jiang $X-1$. An investigation of viral vectors and hosts in "Fever with Thrombocytopenia syndrome". Shandong university; 2012.

36. Yun SM, Lee WG, Ryou J, Yang SC, Park SW, Roh JY, et al. Severe fever with thrombocytopenia syndrome virus in ticks collected from humans, South 
Korea, 2013. Emerg Infect Dis. 2014;20(8):1358-61. https://doi.org/10. 3201/eid2008.131857.

37. Li ZF, Hu JL, Bao CJ, Li PF, Qi X, Qin YF, et al. Seroprevalence of antibodies against SFTS virus infection in farmers and animals, Jiangsu, China. J Clin Virol. 2014;60(3):185-9. https://doi.org/10.1016/j.jcv.2014.03.020.

38. Ni HX, Yang F, Li YD, Liu WB, Jiao SL, Li ZX, et al. Apodemus agrarius is a potential natural host of severe fever with thrombocytopenia syndrome (SFTS)-causing novel bunyavirus. J Clin Virol. 2015;71:82-8. https://doi. org/10.1016/j.jcv.2015.08.006.

39. Niu GY, Li JD, Liang MF, Jiang XL, Jiang $M$, Yin $H Y$, et al. Severe fever with thrombocytopenia syndrome virus among domesticated animals, China. Emerg Infect Dis. 2013;19(5):756-63. https://doi.org/10.3201/eid1905. 120245.

40. Diang SJ, Yin HY, Xu XH, Liu GS, Jiang SX, Wang WQ, et al. A cross-sectional survey of severe fever with thrombocytopenia syndrome virus infection of domestic animals in Laizhou City, Shandong Province, China. Jpn J Infect Dis. 2014;67(1):1-4. https://doi.org/10.7883/yoken.67.1.

41. Li P, Tong ZD, Li KF, Tang A, Dai YX, Yan JB. Seroprevalence of severe fever with thrombocytopenia syndrome virus in China: a systematic review and meta-analysis. Plos One. 2017;12:4. https://doi.org/10.1371/journal. pone.0175592.

42. Gu S, Wu X, Zhou B, Ling F, Zhang H, Huang Y, et al. Epidemiological investigation on an outbreak of severe fever with thrombocytopenia syndrome in northwest Zhejiang province. Zhonghua Liu Xing Bing Xue Za Zhi. 2015;36(4):364-7.

43. Kurihara S. Severe fever with thrombocytopenia syndrome. Rinsho Byori. 2016;64(9):1052-6.

44. Liu S, Chai C, Wang C, Amer S, Lv H, He H, et al. Systematic review of severe fever with thrombocytopenia syndrome: virology, epidemiology, and clinical characteristics. Rev Med Virol. 2014;24(2):90-102. https://doi. org/10.1002/rmv. 1776.

45. Zhao ZY, Chen Q, Zhao B, Hannah MN, Wang N, Wang YX, et al. Relative transmissibility of shigellosis among male and female individuals: a modeling study in Hubei Province China. Infect Dis Poverty. 2020;9(1):39. https://doi.org/10.1186/s40249-020-00654-x.

46. Saijo M. Pathophysiology of severe fever with thrombocytopenia syndrome and development of specific antiviral therapy. I Infect Chemother. 2018;24(10):773-81. https://doi.org/10.1016/j.jiac.2018.07.009.

47. Li H, Zhang LK, Li SF, Zhang SF, Wan WW, Zhang YL, et al. Calcium channel blockers reduce severe fever with thrombocytopenia syndrome virus
(SFTSV) related fatality. Cell Res. 2019;29(9):739-53. https://doi.org/10. 1038/s41422-019-0214-z.

48. Ham H, Jo S, Jang J, Choi S. No detection of severe fever with thrombocytopenia syndrome virus from ixodid ticks collected in Seoul. Korean J Parasitol. 2014;52(2):221-4. https://doi.org/10.3347/kjp.2014. 52.2.221

49. Kim BJ, Kim H, Won S, Kim HC, Chong ST, Klein TA, et al. Ticks collected from wild and domestic animals and natural habitats in the Republic of Korea. Korean J Parasitol. 2014;52(3):281-5. https://doi.org/10.3347/kjp. 2014.52.3.281.

50. Nakayama S, Kobayashi T, Nakamura A, Yoshitomi H, Song YDJ, Ashizuka Y. Detection of borrelia DNA in tick species collected from vegetation and wild animals in Fukuoka, Japan. Jpn J Infect Dis. 2020;73(1):61-4. https:// doi.org/10.7883/yoken.JIID.2019.146.

51. Li ZF, Bao CJ, Hu JL, Liu WD, Wang XC, Zhang L, et al. Ecology of the tick-borne phlebovirus causing severe fever with thrombocytopenia syndrome in an endemic area of China. Plos Neglect Trop D. 2016;10:4. https://doi.org/10.1371/journal.pntd.0004574.

52. Ryu BH, Kim JY, Kim T, Kim MC, Kim MJ, Chong YP, et al. Extensive severe fever with thrombocytopenia syndrome virus contamination in surrounding environment in patient rooms. Clin Microbiol Infec. 2018;24:8. https://doi.org/10.1016/..cmi.2018.01.005.

53. Xing XS, Guan XH, Liu L, Xu JQ, Li GM, Zhan JB, et al. A case-control study of risk sources for severe fever with thrombocytopenia syndrome in Hubei Province, China. Int J Infect Dis. 2017;55:86-91. https://doi.org/10. 1016/j.jijid.2017.01.003.

54. Jia B, Wu WH, Huang R, Wang GY, Song PX, Li Y, et al. Characterization of clinical features and outcome for human-to-human transmitted severe fever with thrombocytopenia syndrome. Infect Dis-Nor. 2018;50(8):601-8. https://doi.org/10.1080/23744235.2018.1449962.

55. Bao CJ, Qi X, Wang H. A novel bunyavirus in China. N Engl J Med. 2011;365(9):862-3. https://doi.org/10.1056/NEJMc1106000.

\section{Publisher's Note}

Springer Nature remains neutral with regard to jurisdictional claims in published maps and institutional affiliations.
Ready to submit your research? Choose BMC and benefit from:

- fast, convenient online submission

- thorough peer review by experienced researchers in your field

- rapid publication on acceptance

- support for research data, including large and complex data types

- gold Open Access which fosters wider collaboration and increased citations

- maximum visibility for your research: over 100M website views per year

At $\mathrm{BMC}$, research is always in progress.

Learn more biomedcentral.com/submissions 